\title{
USO DE RECEPTORES GPS DE 100 HZ NA DETECÇÃO DE DEFLEXÕES VERTICAIS MILIMÉTRICAS DE PONTES DE CONCRETO DE PEQUENO PORTE
}

\author{
The use of GPS at a rate of $100 \mathrm{HZ}$ to detect millimetric vertical deflections of \\ small sized concrete bridges
}

\author{
ANA PAULA CAMARGO LAROCCA ${ }^{1}$ \\ JOÃO OLYMPIO DE ARAÚJO NETO ${ }^{2}$ \\ JORGE LUIZ ALVES TRABANCO ${ }^{3}$ \\ AUGUSTO CÉSAR BARROS BARBOSA ${ }^{4}$ \\ ANDRÉ LUIZ BARBOSA NUNES DA CUNHA ${ }^{1}$ \\ RICARDO ERNESTO SCHAAL 5

\begin{abstract}
${ }^{1}$ Universidade de São Paulo, Escola de Engenharia de São Carlos (EESC-USP) - São Carlos, SP, Brasil larocca.ana@usp.br, acunha@sc.usp.br

${ }^{2}$ Instituto Federal de Educação, Ciência e Tecnologia (IFSULDEMINAS) - Inconfidentes, MG, Brasil joao.olympio@ifsuldeminas.edu.br

${ }^{3}$ Universidade Estadual de Campinas, Faculdade de Engenharia Civil (UNICAMP) - Campinas, SP, Brasil trabanco@fec.unicamp.br

${ }^{4}$ Universidade Estadual do Ceará, Centro de Ciências e Tecnologia (UECE-CCT) - Fortaleza, CE, Brasil barbosaiag@gmail.com

${ }^{5}$ Universidade de São Paulo, Escola Politécnica (EPUSP) - São Paulo, SP, Brasil - schaal@ sc.usp.br
\end{abstract}

\section{Resumo:}

As últimas quatro décadas foram importantes para o desenvolvimento da malha rodoviária brasileira. O país recebeu incentivos financeiros para a sua expansão e diversas soluções estruturais para pontes e viadutos foram criadas. Em paralelo a este desenvolvimento, houve nos últimos anos um crescimento significativo dessas estruturas em estágio avançado de deterioração devido à ausência de programas de manutenção preventiva. Dessa maneira, este trabalho propõe o uso de receptores GPS num plano de monitoramento de curta duração para acompanhar o comportamento estrutural de uma ponte rodoviária curva de concreto armado já em serviço. E apresenta os primeiros resultados da pesquisa com a portadora L1 do sistema GPS e dados gravados com taxa de $100 \mathrm{~Hz}$, no monitoramento do vão central de ponte de concreto de pequeno porte situada sobre o Rio Jaguari, na cidade de Extrema, divisa entre os Estados de Minas Gerais e São Paulo. O desafio reside no fato de que estruturas como estas - pontes de concreto de pequeno e médio porte - respondem pela grande maioria das obras de arte da malha rodoviária brasileira e por serem 
estruturas rígidas, apresentam deflexões verticais pequenas, de até $5 \mathrm{~mm}$. O experimento foi realizado por meio de sessões de observações com receptores GPS sobre a ponte, no vão instrumentado por equipamentos convencionais para posterior confrontação de resultados entre os receptores GPS e os métodos clássicos de monitoramento. A ferramenta de filtragem Continuos Wavelet Transform (CWT) foi utilizada para analisar as frequências de resposta da ponte a partir dos resíduos da dupla diferença de fase da portadora L1. A análise do espectro de energia da CWT gerado a partir dos dados coletados com os receptores GPS indicou alta concentração de energia nas mesmas faixas de frequência - de resposta do tabuleiro da ponte - apontadas pela Modelagem por Elementos Finitos e pela prova de carga dinâmica.

Palavras-chave: Monitoramento; Ponte de Concreto; GPS; Filtragem de Sinais; Ondeleta de Morlet; Transformada Continua Wavelet.

\begin{abstract}
:
The last four decades were important for the Brazilian highway system. Financial investments were made so it could expand and many structural solutions for bridges and viaducts were developed. In parallel whit this development, there was a significant raise of pathologies in these structures, due to lack of maintenance procedures. Thus, this paper purposes the use of GPS to create a short-term monitoring plan in order to check the structural behavior of a curved highway concrete bridge in current use. And it present the first results of the research with the L1 GPS carrier frequency and recorded data at a rate of $100 \mathrm{~Hz}$, at the monitoring center span of small concrete bridge located on the Jaguari River, in the city of Extreme which borders Minas Gerais and São Paulo states. The challenge lies in the fact that such structures, small and medium-sized concrete bridges, account for the vast majority of art works of Brazilian highways and, as they are rigid structures, small present up to $5 \mathrm{~mm}$ vertical deflections. This experiment was carried out through observations sessions with GPS receivers over the bridge at the span instrumented by conventional structural equipment for further confrontation of results between GPS receivers and classic methods of monitoring. The Continuous Wavelet Transform (CWT) was used to analyze the frequency of the response of the bridge from the residues of double difference carrier phase L1.The analysis of the CWT energy spectrum generated from the data collected with GPS receivers indicated a high concentration of energy in the same frequency bands - of the bridge deck response identified by the Finite Element Modeling and the dynamic load test.
\end{abstract}

Keywords: Monitoring; Concrete Bridge; GPS; Filtering Signals; Morlet;Wavelet; Continuous Wavelet Transform.

\title{
1. INTRODUÇÃO
}

Houve nos últimos anos no Brasil um crescimento significativo de obras de arte especiais (OAEs) que apresentaram deterioração precoce causada pela ausência de programas de manutenção preventiva dessas estruturas. Embora o Brasil apresente órgãos regulamentadores que fornecem todo o procedimento para a inspeção e garantia da integridade de OAEs, em grande parte dos casos, as patologias são detectadas e as providências são tomadas apenas quando a deterioração da estrutura atinge um estado crítico ou quando oferece risco aos usuários. Um estudo feito pelo SINAENCO (Sindicato Nacional das Empresas de Arquitetura e Engenharia Consultiva), intitulado "Infra-Estrutura da Cidade: Prazo de Validade Vencido" mostra a necessidade de uma política permanente de manutenção de estruturas e administração dos recursos. Em relação às 
obras de arte especiais na cidade de São Paulo, o estudo mostra que há 240 pontes e viadutos em estado de deterioração, apresentando diversas patologias, e oferecendo risco aos usuários. Um dos principais fatores em destaque para a deterioração é atribuído ao investimento ínfimo em manutenção nos últimos anos, correspondente a $0,38 \%$ do custo final das obras (Sinaenco, 2011; Andrade et al., 2013). A deterioração se reflete de diversas formas, como exposição de armaduras por falta de manutenção ou provocada por batidas de caminhões com excesso de altura, com consequente carbonatação; trincas, rachaduras com mais de $3 \mathrm{~cm}$ de espessura, eflorescência e lixiviação; desplacamento com pontos de infiltração; solapamento de taludes na região dos pilares; pilares com segregação da seção (http://www.sinaenco.com.br/default.asp). A consequência da falta de manutenção periódica nestas estruturas é a necessidade de intervenções mais onerosas e de maior porte.

Este trabalho apresenta os resultados parciais do monitoramento dinâmico de oscilações de um dos vãos do tabuleiro de uma ponte de concreto, com o uso do Sistema de Posicionamento Global (GPS) (Araújo Neto et al., 2014). Os ensaios apresentados a seguir fazem parte da continuidade do desenvolvimento de um método, iniciado em 2002 (Schaal e Larocca, 2002), denominado como Método dos Resíduos de Fase (MRF). Esta pesquisa busca melhorar o limiar de detecção do Global Positioning System (GPS), a partir do MRF, para que possa ser utilizado, também, no monitoramento dinâmico de pontes rígidas de pequeno porte. Até o momento, a aplicação do MRF era concentrada no monitoramento de oscilações de pontes suspensas e estaiadas de médio e grande porte (Larocca, 2004; Larocca et al., 2005; Larocca e Schaal, 2010; Larocca et al., 2011; Schaal et al., 2012; Larocca et al., 2013). Este método apresentava como grande desvantagem em 2004, a necessidade de programar o horário de coleta de dados em relação ao horário que apresentasse satélites com elevação maior de $80^{\circ}$, fato que foi mitigado com a introdução de maior número de satélites na constelação do sistema GPS.

Devido ao parque de obras de arte da malha rodoviária brasileira ser notadamente constituída por pontes de concreto de pequeno e médio porte, se fez necessário dar continuidade ao desenvolvimento do método. O propósito é que a facilidade e praticidade de utilização do GPS como instrumento de monitoramento de oscilações dinâmicas de pontes de concreto de pequeno e médio porte - possam ser largamente utilizadas pela engenharia, também no Brasil.

O Método dos Resíduos de Fase utiliza as observações GPS da portadora L1 transmitidos por apenas dois satélites da constelação GPS disponível no momento. Os dados dos sinais destes satélites são registrados pelos receptores GPS móvel, fora da estrutura. O método inclui a utilização de um oscilador eletromecânico com amplitude conhecida e especialmente projetado para instalar a antena GPS, o que permite a calibração do grau e frequência de oscilação presente na estrutura. Os resultados apresentados a seguir são oriundos de testes de campo iniciais realizados sobre uma ponte constituída por concreto armado localizada na Rodovia Fernão Dias cidade de Extrema, sul de Minas Gerais.

\section{EMBASAMENTO TEÓRICO DO MÉTODO UTILIZADO}

O método usado neste artigo utiliza os dados do sistema de posicionamento GPS, os quais são transmitidos pela fase da portadora L1, com base no princípio da interferometria de Michelson (Kumar, 2004), já publicados em trabalhos anteriores, como em Schaal e Larocca, 2002; Larocca, 2004; Schaal e Larocca, 2009; Larocca et al., 2010; Larocca et al., 2013. Essa metodologia, resumidamente, consiste na aplicação do princípio da interferência sobre os sinais transmitidos pelos satélites da constelação GPS para realizar medições de distâncias através da alteração da fase 
provocada em um dos sinais. Neste caso, um receptor GPS é instalado sobre a estrutura a ser monitorada e o outro receptor que fica instalado numa base com coordenadas conhecidas; que é responsável pelas correções diferenciais. Na Figura 1 está ilustrada uma antena GPS fixada no vão central de uma ponte suspensa, sob ação de uma carga dinâmica - no caso, pela travessia de um caminhão. A frequência e a amplitude de oscilação do vão central podem ser determinadas com base na análise dos sinais GPS coletadas (Guo, 2005; Larocca e Schaal, 2005; Yi et al., 2010, 2013; Im et al., 2013).

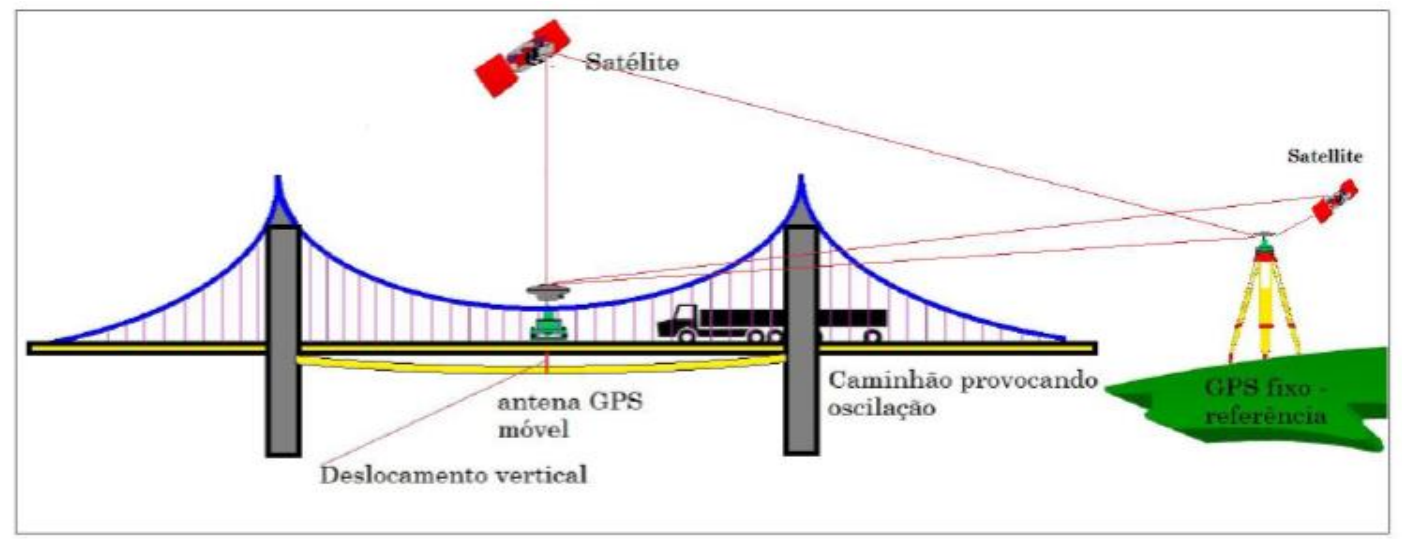

Figura 1: Antena GPS do receptor móvel sobre a ponte (Araújo Neto et al.,2013).

O método utilizado, baseado no princípio do interferômetro de fase, requer apenas a coleta de dados emitidos por dois satélites, com ângulo de fase maior que $80^{\circ}$ e não mais de uma constelação com mais de quatro satélite (Larocca, 2004). Assim, para se medir um deslocamento vertical, por exemplo, é necessário que um satélite esteja com elevação próxima a $90^{\circ}$ e outro com elevação próxima à linha do horizonte (Figura 2). No processamento da dupla diferença de fase, o satélite com baixa altitude é considerado como o satélite de referência, o qual permite obter o vetor dos resíduos do satélite com maior altitude, denominado aqui de 'satélite medidor'.

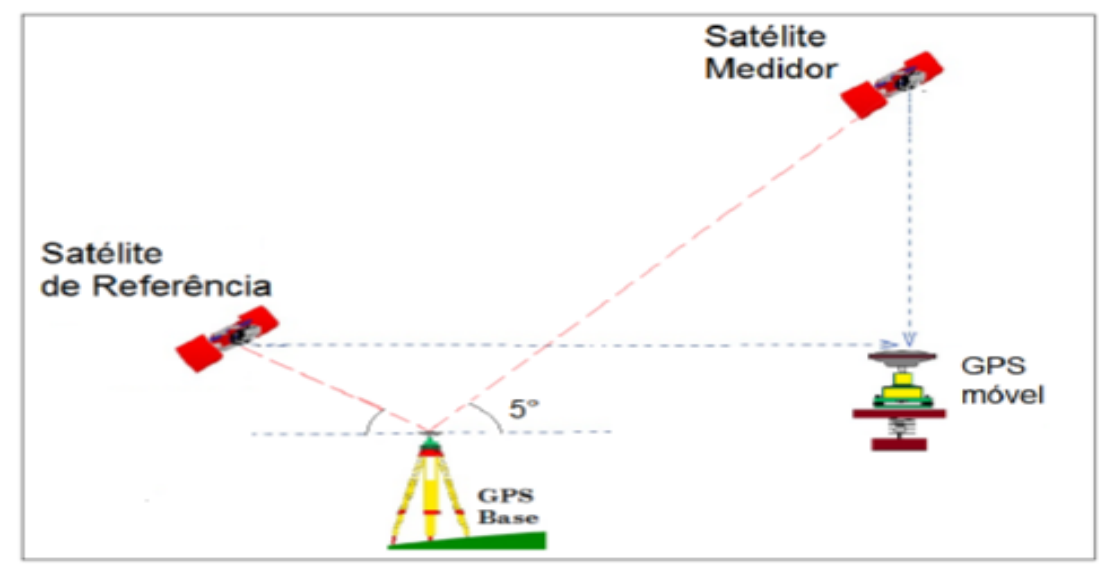

Figura 2: Satélite de referência e Satélite de medição (Araújo Neto et al., 2013).

\subsection{Oscilador Eletro-Mecânico}


Para calibrar a medição dos deslocamentos dinâmicos previamente desconhecidos na estrutura, foi desenvolvido em estudos anteriores um oscilador eletromecânico (OEM). O OEM aplica movimentos verticais controlados, em relação à amplitude e velocidade de deslocamento, na antena do receptor GPS que sofrerá os movimentos da estrutura.

A Figura 3 apresenta uma antena GPSJAVAD (modelo - RegAnt_DD JAVAD), acoplada sobre o oscilador eletromecânico, o qual foi instalado sobre o pilar geodésico do IBGE, para a realização de experimentos preliminares com diferentes amplitudes e frequências.

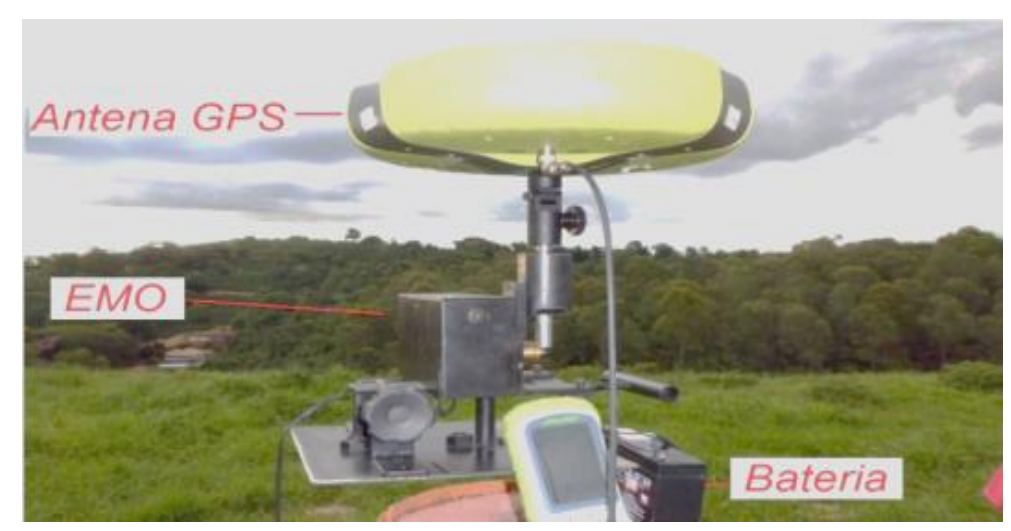

Figura 3: Detalhamento do Oscilador Eletromecânico com a antena JAVAD.

\subsection{Análise Espectral dos Dados}

A análise espectral dos resíduos resultantes do processamento GPS da dupla diferença de fase foi realizada utilizando-se a Continuous Wavelet Transform utilizando-se a Ondaleta-mãe (wavelet mãe) de Morlet (Daubechies, 1992; Morlet, 1983).

A transformada Wavelet permite avaliar analisar variações espectrais com diferentes resoluções em tempo-frequência-espaço. Esta técnica é também indicada em aplicações específicas, tais como os métodos para remoção de ruídos, pois esta se utiliza da fundamentação matemática extraída dos métodos clássicos desenvolvidos por Joseph Fourier (comumente conhecida como Transformada de Fourier). Isto significa que um sinal pode ser mapeado num plano tempo-escala, através de um escalograma (Goswami e Chan, 2011; Nguyen et al., 2010; Souza et al., 2009).

A CWT envolve um conjunto de operações "lineares" (convolução), as quais podem ser utilizadas no estudo de sinais não-estacionários para a extração de informação de variações de frequência e para detectar oscilações das estruturas localizadas na escala do tempo com sua localização espacial. Esta técnica tem sido amplamente utilizada em várias áreas de pesquisa e aplicações, por exemplo: em análise geofísica, hidrologia, dados climáticos, medicina, estudo do som, análise de dados de GPS, dentre outros estudos relacionados ao monitoramento de estruturas (Moschas et al., 2012; Beshr e Kaloop, 2013; Azarbad e Mosavi, 2013; Kaloop et al., 2013).

A escolha do uso da CWT com a Wavelet-mãe (Ondaleta-mãe) de Morlet foi estratégica, visto que os sinais analisados não são simultaneamente representados em tempo e em frequência pela Transformada clássica de Fourier, por serem não-estacionários, além de apresentarem energias 
bem distintas. Adicionalmente, estes sinais apresentam pequena amplitude pico a pico (de até5 $\mathrm{mm}$ ) em região de baixa frequência.

Para este fim, e como mencionado anteriormente, utilizou-se a Ondaleta-mãe de Morlet, aqual é definida da seguinte forma (Morlet, 1983):

$$
\Psi_{o}(\eta)=\pi^{-1 / 4} e^{i w_{o} \eta} e^{-1 / 2 \eta^{2}}
$$

onde:

$w_{o}$ é a frequência de corte adimensional e

$\eta$ é o tempo adimensional.

Quando se utiliza este tipo de filtro para fins de extração de características de uma série temporal a waveletde Morlet é uma boa escolha, uma vez que proporciona excelente equilíbrio entre o tempo e a localização de frequência. A ideia proposta pela CWT é a sua aplicabilidade como um filtro passa-banda para as séries temporais.

A CWT de uma série temporal, $\{\mathrm{f}(\mathrm{t}), \mathrm{t}=1, \ldots, \mathrm{N}\}$, com intervalos de tempo distribuídos uniformemente por dt é definida como a convolução f(t) com a Ondaleta-mãe de Morlet, escalada e normalizada, conforme Equação (2) (Morettin, 2014):

$$
W_{j, k}(t)=\frac{1}{\sqrt{j}} \int_{t=1}^{N} f(t) \Psi_{o}\left(\frac{t-k}{j}\right) d t
$$

Sendo $\mathrm{Wj}, \mathrm{k}(\mathrm{t})$ a similaridade entre a função Ondaleta-mãe e a série temporal analisada $f(\mathrm{t})$, ou seja, quanto mais alto o valor de $\mathrm{Wj}, \mathrm{k}(\mathrm{t})$, maior a semelhança entre a função analisada e a função Ondaleta de Morlet, a qual modula o sinal analisado.

Para uma função ser considerada de Função Ondaleta-mãe, representada por $\Psi_{0}$, é necessário satisfazer as seguintes propriedades fundamentais:

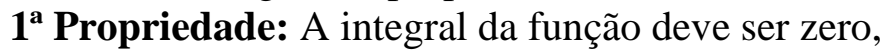

$$
\int_{-\infty}^{+\infty} \Psi_{0}(\mathrm{t}) \mathrm{dt}=0
$$

A Equação (3) assegura que a WF assuma uma forma de tipo onda. Esta condição é conhecida como uma condição de "admissibilidade". Isso assegura a existência da "Transformada Inversa em Ondaletas", na composição da série original.

$2^{\mathbf{a}}$ Propriedade: Deve possuir energia unitária, i.e.,

$$
\int_{-\infty}^{+\infty}\left|\Psi_{0}(\mathrm{t})\right|^{2}=1
$$

A Equação (4) garante que a WF apresente suporte compacto, ou seja, um decaimento rápido de amplitude (do inglês e-foldingtime), o que garante que a Ondaleta-mãe apresente localização espacial, trata-se do grande diferencial em relação à Transformada Clássica de Fourier.

\section{PONTE DE CONCRETO SOBRE O RIO JAGUARI, MINAS GERAIS}

A ponte está situada numa porção da Rodovia Fernão Dias - BR 381, km 947, do acesso sentido sul da cidade de Extrema no sul de Minas Gerais, próximo à divisa com o Estado de São Paulo (Figura 4). 


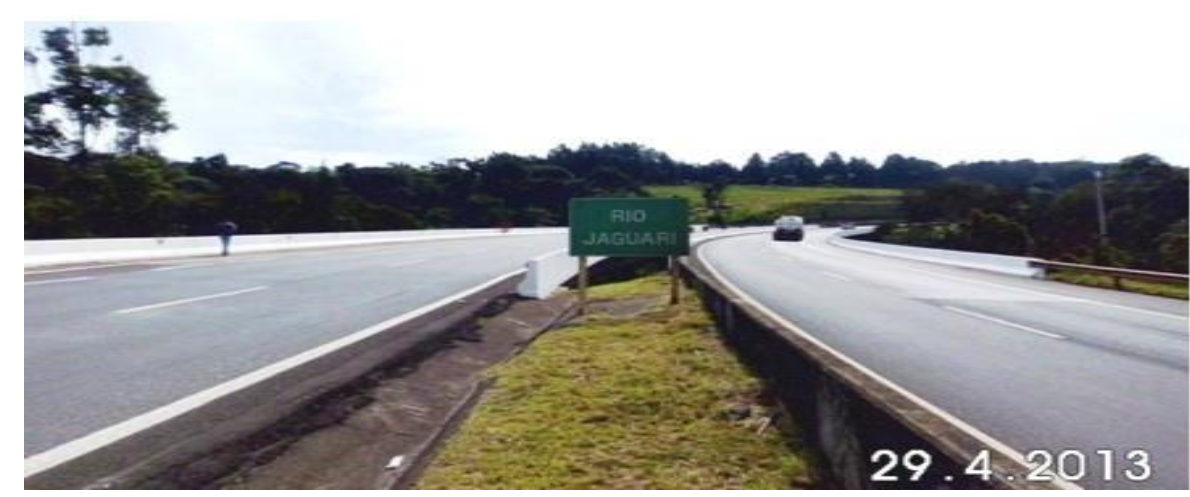

Figura 4: Ponte em estudo, sobre o rio Jaguari (Fonte: Andrade et al., 2013)

Nesta fase do estudo optou-se pela ponte sul em função de sua característica e do tráfego no local. A largura total do tabuleiro é de 11,7 m, destes 10,9 m são divididos pelas duas faixas de tráfego e por uma faixa de acostamento, mais $0,4 \mathrm{~m}$ para todos os guarda-rodas do tipo New-Jersey constituídos em concreto armado (Andrade et al., 2013).

\subsection{Identificação dos Valores de Deflexão Vertical e Frequências esperados para o Tabuleiro da Ponte}

Os valores da amplitude da deflexão vertical e frequência de vibração do tabuleiro do vão de 30 metros foram obtidos por duas formas - através da Modelagem por Elementos Finitos e através de prova de carga dinâmica sobre o tabuleiro da ponte, respectivamente. Estes valores foram considerados como referência e serviram como elemento de confirmação sobre a detecção, ou não, através o uso de receptores GPS sob o MRF e CWT.

A modelagem numérica da ponte sobre o rio Jaguari foi realizada com base no Método dos Elementos Finitos (MEF) utilizados os softwares SAP2000 ${ }^{\circledR}$ V14 e Midas Fx+ for DIANA ${ }^{\circledR}$. Maiores detalhes dos modelos poderão ser conferidos em Andrade et al. (2013).O conteúdo espectral analisado permitiu a verificação das frequências mais excitadas, as quais correspondem às primeiras frequências no plano vertical longitudinal da ponte. Estas frequências permaneceram na faixa dos 5 a $10 \mathrm{~Hz}$. E desta forma, nortearam a indicação das frequências que deveriam também, ser identificadas com os receptores GPS, o MRF e a CTW.

A Figura 5 apresenta a identificação e localização dos acelerômetros utilizados na campanha de monitoramento realizada em 2011. Os dados da sessão S1 foram os comparados com os valores indicados pelo tratamento dos dados coletados comGPS. 


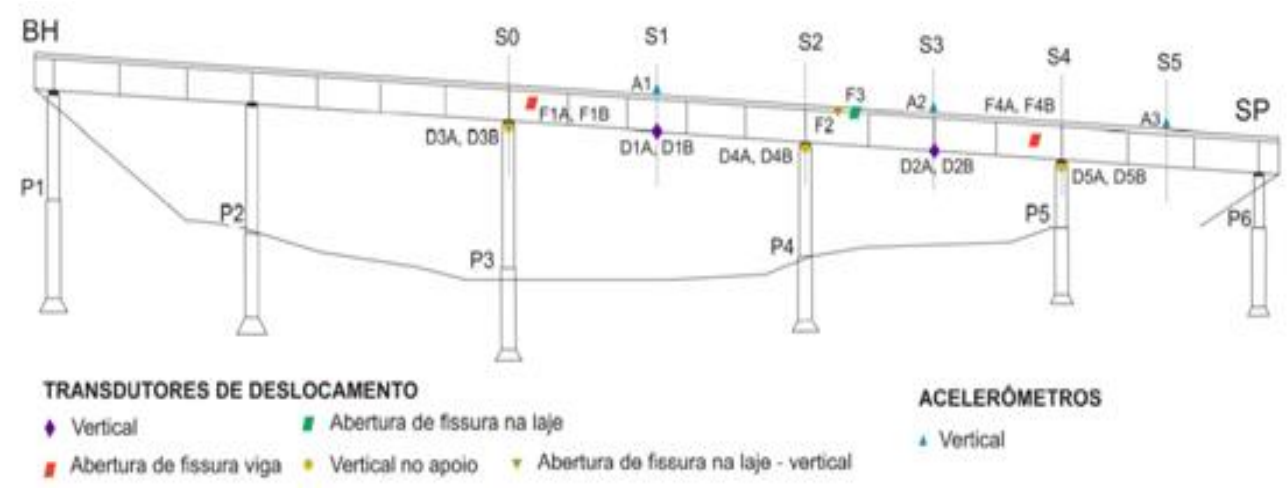

Figura 5: Layout da instrumentação da sessão S1 no vão de $30 \mathrm{~m}$ da ponte do rio Jaguari (Andrade et al., 2013)

A Tabela 1 apresenta o valor de deflexão vertical esperado com base nos resultados da análise linear, indicando deslocamento no meio do vão de $3,55 \mathrm{~mm}$.

Tabela 1: Análise Linear: Comparativo deslocamento vertical Longarina LB (vãode $30 \mathrm{~m}$ ) (Andrade et al., 2013).

\begin{tabular}{c|c|c|c}
\hline \multirow{2}{*}{$\begin{array}{c}\text { Módulo de Elasticidade } \\
(\mathbf{G P a})\end{array}$} & $\begin{array}{c}|c| \\
\text { Dodelo Numérico } \\
(\mathbf{M N})\end{array}$ & $\begin{array}{c}\text { Veículo de Prova } \\
\text { (VP) }\end{array}$ & $\begin{array}{c}\text { Erro relativo } \\
(\%)\end{array}$ \\
\cline { 2 - 3 } & 2,933 & 3,55 & 17,37 \\
24,68 & 3,047 & & 14,16 \\
\hline
\end{tabular}

A etapa de realização de ensaios com carga dinâmica - monitoramento de curta duração com tráfego controlado - ocorreu no dia 10 de outubro de 2011. A realização desta etapa exigiu a interrupção do tráfego para a passagem do veículo com peso e velocidade conhecidos, denominado veículo de prova ou veículo teste.E através deste ensaio se teve a confirmação dos valores da frequência de vibração indicados pela MEF e esperados para o tabuleiro da ponte (ANTTRDT PROJETO 4 SGP/AFD, 2012; Andrade et al., 2013).

O veículo de prova constituiu de um caminhão de cinco eixos, sendo 2 eixos no cavalo mecânico e 3 eixos no semirreboque, conforme mostra a Figura 6 . O peso total do veículo de prova carregado era de $44,3 \mathrm{t}$.

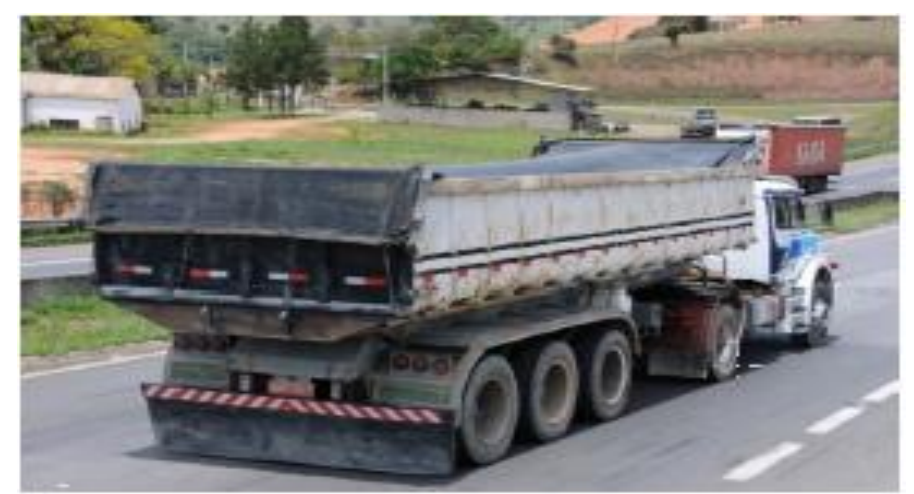

Figura 6: Veículo de prova de carga utilizado no teste na ponte (ANTTRDT PROJETO 4 SGP/AFD, 2012). 
Para avaliar o conteúdo espectral dos registros temporais obtidos nos ensaios dinâmicos foram selecionados os intervalos de tempo em cada registro após a saída do veículo de prova da estrutura da ponte. A Figura 7, a seguir, ilustra a aceleração e as frequências naturais na direção vertical para o monitoramento do tráfego normal.

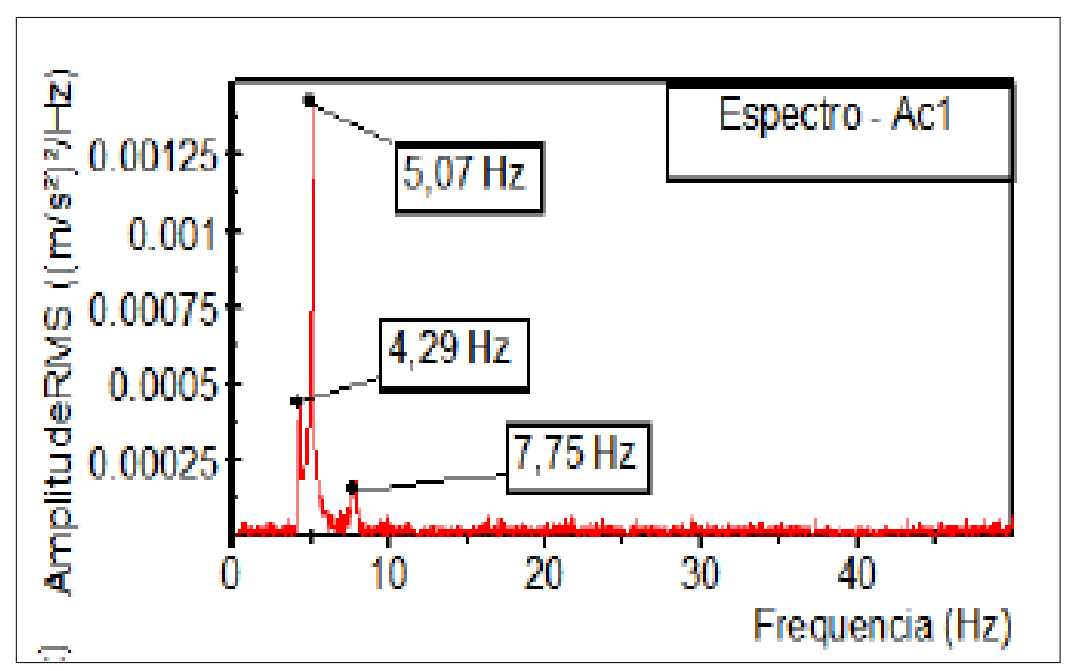

Figura 7: Espectro de aceleração (frequência) na direção vertical para o monitoramento do tráfego normal no dia 10/10/2011(Andrade et al., 2013).

\section{COLETA DE DADOS COM RECEPTOR GPS DE 100HZ}

As análises para testar o GPS como ferramenta para o monitoramento do vão central da ponte foram conduzidas em 4etapas: na primeira realizou-se o transporte de coordenadas para a região próxima da ponte; na segunda utilizou-se apenas o OEM com amplitude e frequência controlada, sobre um marco geodésico para ensaios sobre detecção de deflexões verticais de até $5 \mathrm{~mm}$; na terceira etapaforam feitas observações sobre aponte e a quarta, finalmente, constitui-se da análise de dados e comparação do valores obtidos com os indicados pela MEF e prova de carga dinâmica.

\subsection{Transportes de Coordenada para a Região mais Próxima da Ponte}

O procedimento para caracterizar o comportamento da ponte com o receptor GPS foi feito através do posicionamento relativo estático. Deste modo foi necessária a utilização de um marco geodésico com coordenadas ajustadas.

Na vizinhança da ponte não existia marco geodésico para a determinação relativa das coordenadas relativas da estação GPS sobre a ponte. Em função disso construiu-se um marco geodésico (Figura $8 \mathrm{a}, 8 \mathrm{~b}$ e $9 \mathrm{c}$ ) nas proximidades da ponte e que atendesse às normas e padrão de qualidade proposta pelo IBGE. 

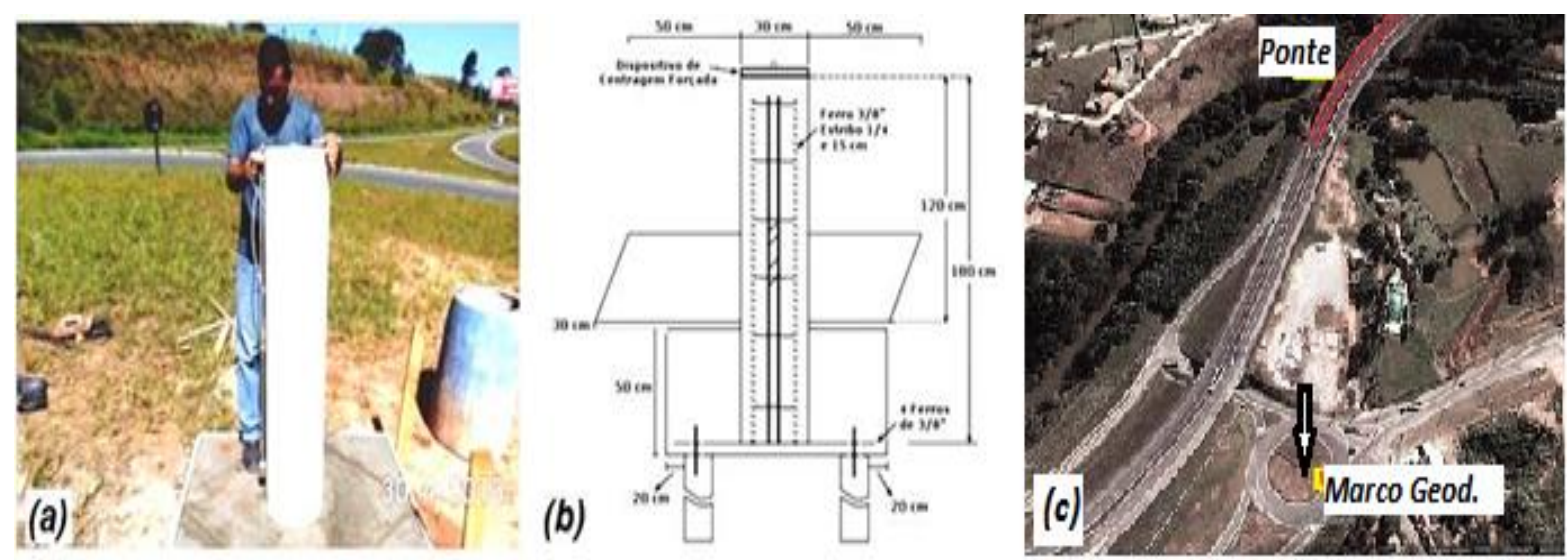

Figura 8: (a) Construção do marco geodésico, (b) Projeto para construção proposto pelo IBGE e (c) Mapa de situação da ponte e marco geodésico.

O local escolhido para a construção do marco geodésico foi o centro de uma rotatória nos limites da faixa de domínio da rodovia Fernão Dias, a 300 m de distância da ponte observada. A Figura 9 ilustra a localização em mapa do marco implantando.

Após a finalização da construção do marco, foi realizado o levantamento dos dados GPS (Figura 9) para o transporte das coordenadas. Este procedimento foi realizado em3dias diferentes, com 6 horas de rastreio, para que o mesmo fosse homologado pelo IBGE, com inclusão na Rede Geodésica Brasileira (RGB), em junho de 2013.

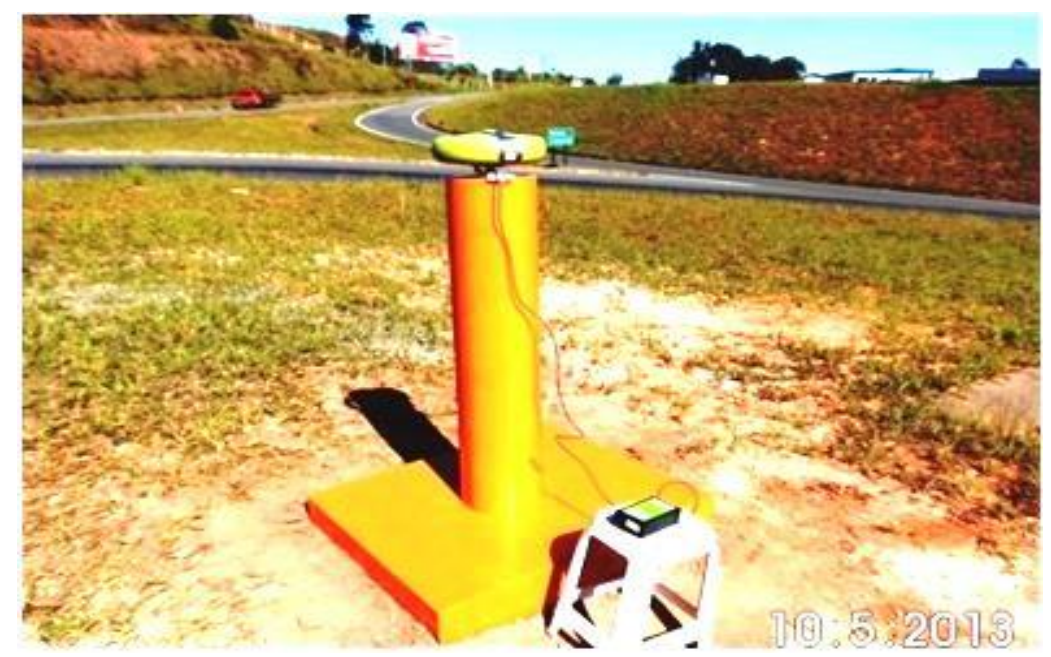

Figura 9: Coleta de dados no Pilar Geodésico para homologação pelo IBGE.

\subsection{Simulações com o OEM}

Antes da coleta dados na ponte foi necessário configurar e testar o dispositivo OEM e o receptor GPS com o objetivo de testar a capacidade do método em detectar, ou não, deslocamento com amplitude inferior a $5 \mathrm{~mm}$, valor este próximo do valor de deflexão esperado para o tabuleiro ponte. Para realizar as medições, a antena do receptor GPS foi instalada sobre o OEM e este sobre 
o marco geodésico do IBGE, localizado no Instituto Federal Sul de Minas Gerais - Campus Inconfidentes, Minas Gerais, conforme ilustração apresentada na Figura 10.

O OEM foi usado para aplicar uma controlada movimentação vertical à antena GPS com frequência e amplitude de $0,4 \mathrm{~Hz}$ e $3,8 \mathrm{~mm}$, respectivamente. Para registrar as observações da constelação GPS, configuraram-se os receptores JAVAD SIGMA com taxa de gravação de 100 Hz para realizar medições durante3 minutos (Larocca et al., 2009).

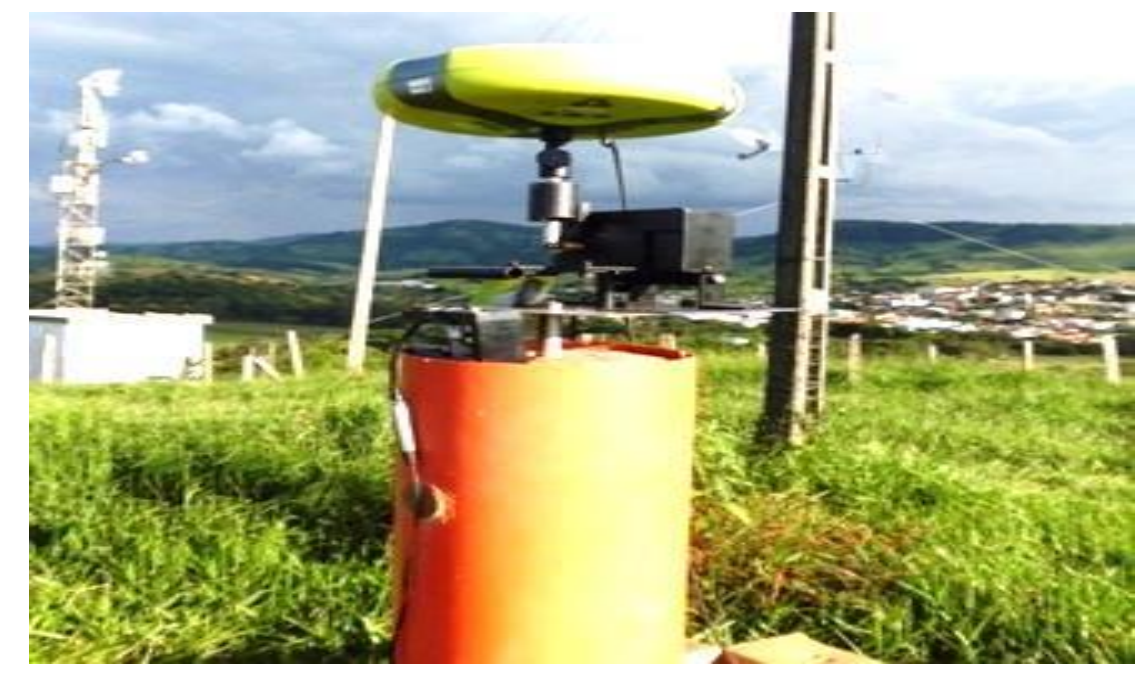

Figura 10: Antena GPS sobre o Oscilador Eletromecânico e Pilar do IBGE no IFSULDEMINAS - Campus Inconfidentes.

\subsection{Resultados das Simulações com o OEM}

De acordo com a Figura 12 (parte inferior) é possível observar o espectro de energia dos resíduos resultantes do processamento GPS da dupla diferença de fase, obtidos com a Ondaleta-mãe de Morlet. O modelo matemático utilizado na geração do espectro foi configurado para evidenciar fenômenos com 5\% de significância estatística, ou seja, 95\% de confiança - cujo nível de significância é limitado pelo contorno representado por uma linha - em preto, dentro do Cone de Influência (Barbosa e Blitzkow, 2008; Barbosa, 2012). O eixo das abscissas corresponde ao número de observações (a cada 0,01 s), o eixo das ordenadas (à esquerda) representa o valor da frequência em Hertz e o eixo das ordenadas (à direita) representa a escala de intensidade de energia com que a frequência é apresentada na área do Cone de Influência. Adicionalmente, na Figura 12 (parte superior), refere-se aos resíduos brutos sem qualquer tipo de tratamento ou filtro, apenas normalizado por $\mathrm{N}-1$, onde $\mathrm{N}$ é o número de observações, oriundos da dupla diferença de fase da portadora L1, devido ao movimento periódico do EMO. Os demais gráficos de energia gerados pelo modelo matemático, no software MATLAB®,seguem o mesmo padrão de descrição.

Ainda, de acordo com a Figura 11, observa-se uma faixa contínua de energia significativa, detectada e representada pela cor vermelha ao longo de todo o período da série temporal, e que corresponde às oscilações programadas e aplicadas pelo EMO na antena móvel, em aproximadamente 0,4 Hz. Entre as observações 3000 e 4000 (Obs1), constata-se registros de energia em torno de $2 \mathrm{~Hz}$ - que devem estar relacionadas com alguma folga no mecanismo do OEM e será investigada em testes futuros. 

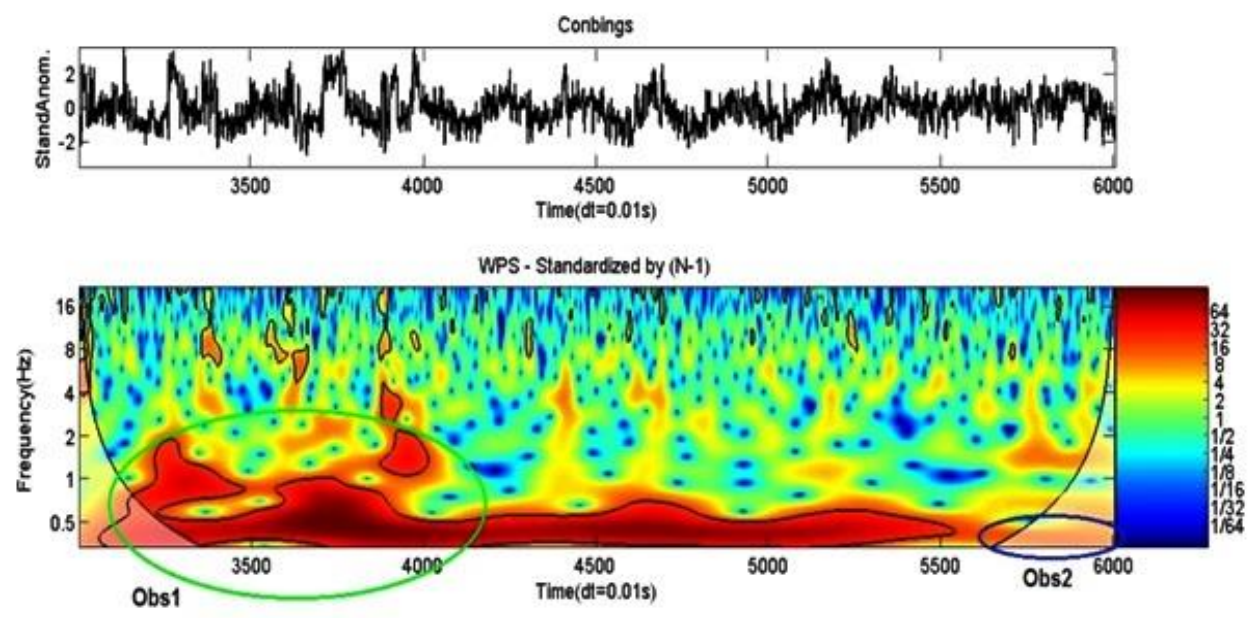

Figura 11: CWT dos resíduos da série temporal em observações entre 3500-5500, com nível de significância em $5 \%$ limitado pelo COI.

Assim, com a possibilidade de detecção de deflexões verticais com amplitude inferior a $5 \mathrm{~mm}$ confirmada, planejou-se a execução de testes na ponte.

Coleta de dados GPS sobrea ponte

Os primeiros ensaios na ponte foram realizados em época distinta às provas de cargas convencionais - a prova de carga foi realizada em 2011 e o monitoramento com receptores GPS em junho de 2013. Novos ensaios estão previstos para ocorrer simultaneamente com prova de carga, instrumentação com acelerômetro e receptores GPS.

\subsection{Layout da Instrumentação}

A instrumentação e coleta de dados GPS ocorreram com a ponte sendo solicitada pelo tráfego local da rodovia.Durante o período de coleta de dados, a ponte foi constantemente excitada pelo tráfego de veículos pesados de diferentes categorias de veículos que passavam pela rodovia. As Figuras 12a e 12 b dispõem de uma imagem com detalhe da estrutura com vista inferior ao tabuleiro e sobre a ponte monitorada, com a antena GPS móvel instalada no guarda corpo através do pino fixado com epóxi. 


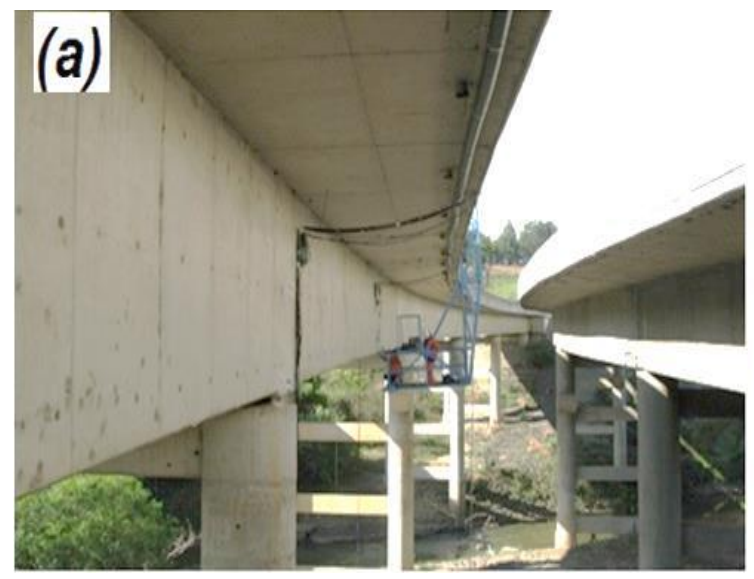

(b)

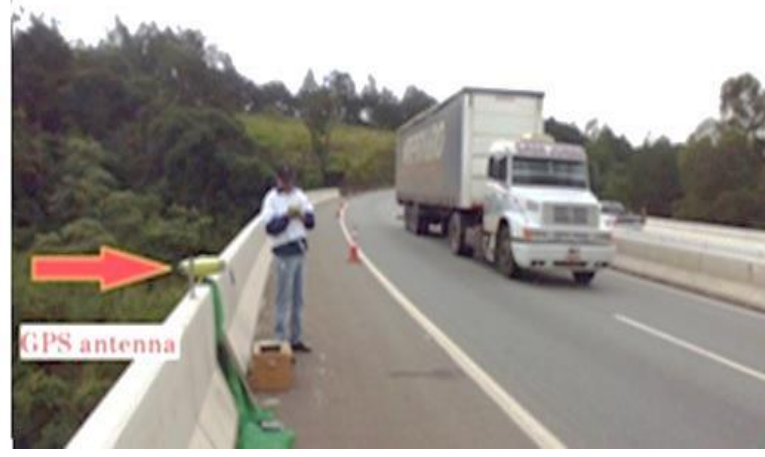

Figura 12: (a) vista inferior da ponte, (b) vista sobre a ponte no momento do rastreio com o receptor GPS.

A Figura 13 ilustra a localização do receptor GPS móvel (rover) sobre o centro do maior vão central da ponte. $\mathrm{O}$ oscilador eletromecânico foi ajustado para aplicar um deslocamento vertical de 3,8 mm e frequência de $0,40 \mathrm{~Hz}$. Houveram duas fases de medições sobre a ponte, uma com a utilização do EMO e a outra sem o dispositivo.

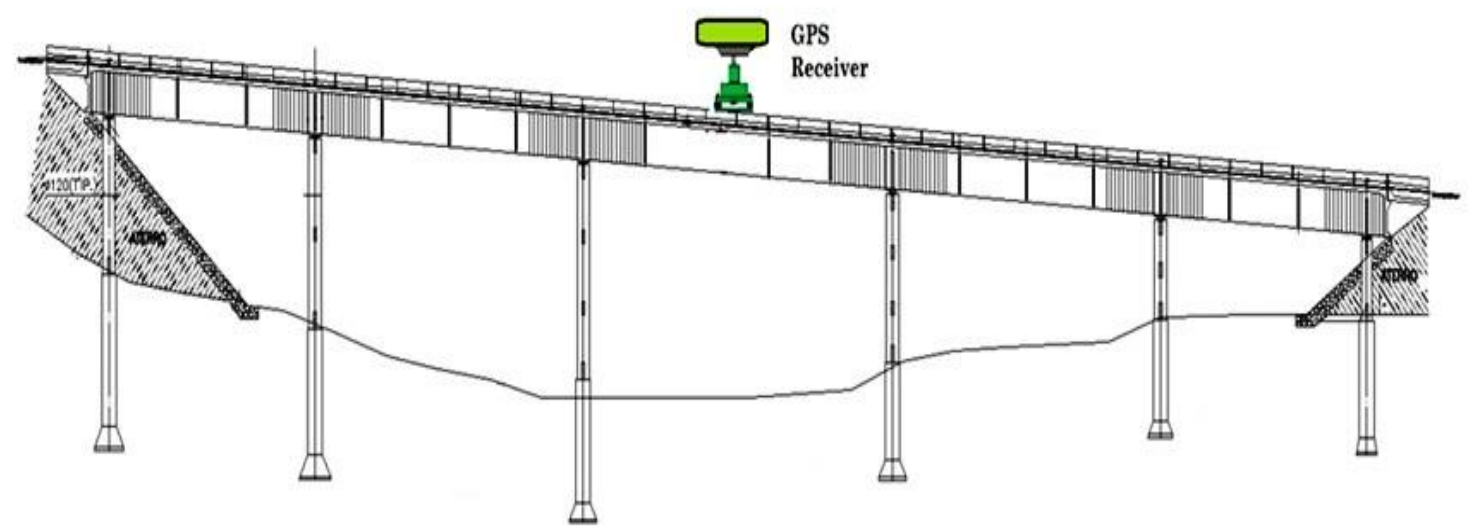

Figura 13: Esboço da ponte com o posicionamento do receptor GPS no vão de $30 \mathrm{~m}$.

\subsection{Coleta de Dados GPS}

Nessa fase do monitoramento, programou-se a coleta de dados GPS pelo denominado modo estático - quando os receptores permanecem estáticos sobre a referência (pilar) e sobre a estrutura (ponte). Assim, instalou-se uma antena GPS sobre a ponte, através de um pino de rosca universal de centragem forçada, fixada no centro do maior vão e borda da ponte, conforme Figura 13b. A outra antena GPS foi instalado sobre o marco geodésico na rotatória conforme mencionado anteriormente.

Para o processamento dos dados coletado sobre a ponte foi utilizado o software Justin JAVAD v. 2.107. Conforme a metodologia apresentada, utilizou-se como referência o satélite número 11,com elevação de $11^{\circ}$,e como satélite "medidor" optou-se pelo satélite 14 , com $87^{\circ}$ de elevação. Os 
posicionamentos instantâneos dos satélites utilizados na medição estão destacados no SKYPLOT (mapeamento da constelação GPS) na Figura 14.

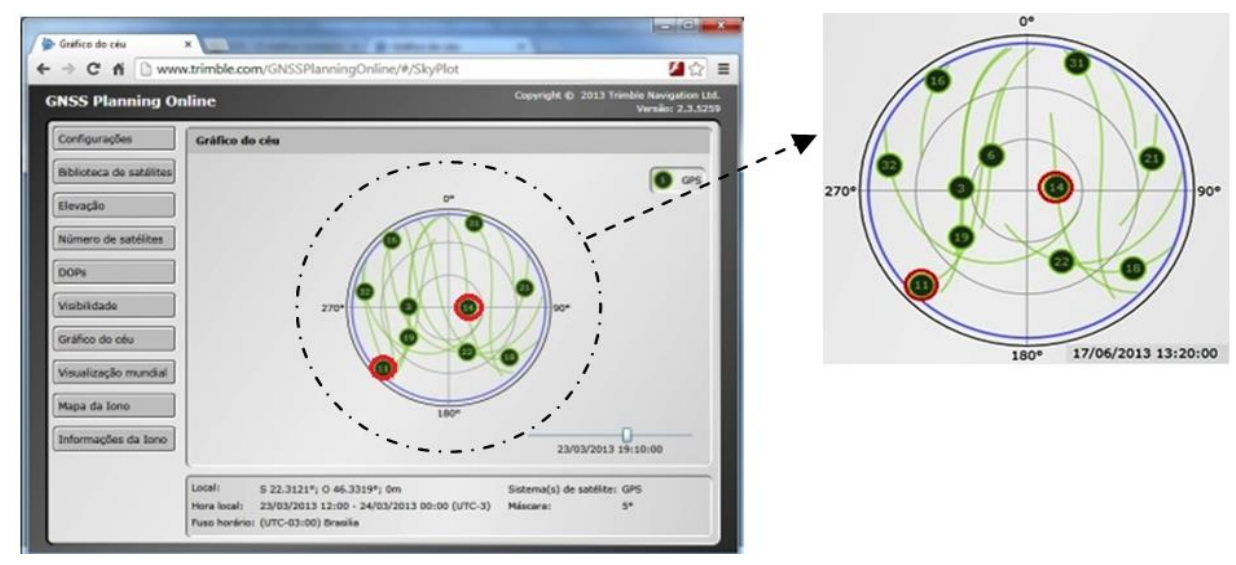

Figura 14: SKYPLOT da Constelação GPS no Experimento da Ponte em 17/06/2013.

\subsection{Análises dos Resultados}

A Figura 15 apresenta os primeiros 20 segundos de dados coletados com uma sequência de 2000 observações, espaçadas de $0,01 \mathrm{~s}$. O primeiro gráfico ilustra os resíduos da dupla diferença de fase processados pelos satélites de número 11 e 14 . Pode-se observar alto nível de energia devido ao multicaminhamento do sinal GPS ao longo da faixa de frequência próximo ao valor de $0,05 \mathrm{~Hz}$. Adicionalmente, pode-se observar alto nível de energia com valores de frequências na faixa de 4 a $8 \mathrm{~Hz}$, que corresponde aos valores de frequências indicados pela MEF (Figura 7) e com os valores obtidos da prova de carga realizada em 2011, indicados na Figura 8.

Desta forma, pode-se afirmar que foi possível identificar tanto as deflexões verticais do tabuleiro de 30 m de vão, bem como as frequências de resposta da estrutura à solicitação do tráfego local.

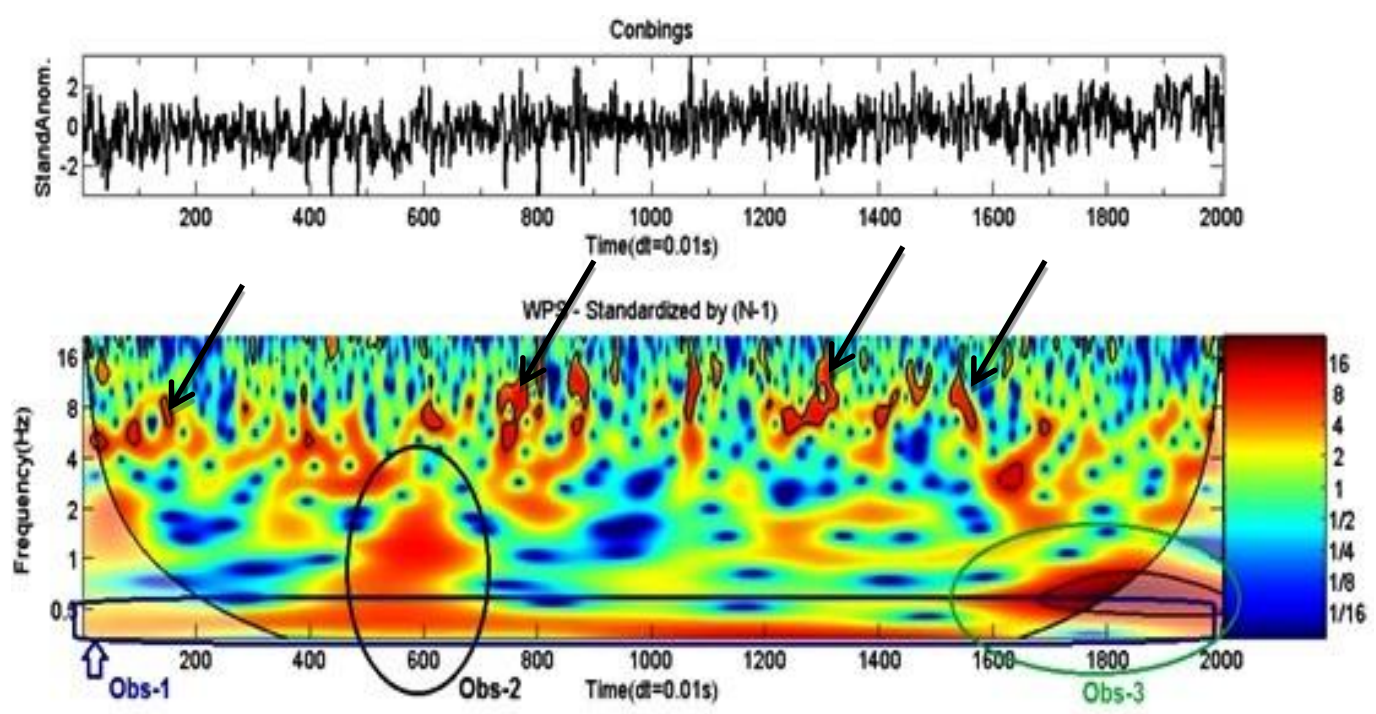

Figura 15: CWT dos resíduos da série temporal em observações entre 0-2000, com nível de significância em $5 \%$ limitado pelo COI. 
Observa-se, ainda, alto nível de energia na região com períodos de 600 e de 1800 e indicados pelas elipses desenhadas sobre a figura 15. Neste estágio na pesquisa, fica a suposição de que se podem indicar a resposta do tabuleiro à passagem de veículos maiores como bitrens e ou rodotrens.

$\mathrm{Na}$ Figura 16, observam-se dados coletados nos 20 segundos seguintes (aos da Figura 16). Dentro do cone de influência (COI), observam-se novamente três regiões, definidas por A, B e C, com elevado nível de energia possivelmente devido à passagem de veículos mais pesados conforme mencionado anteriormente. Por outro lado, são identificadas as frequências na faixa de $4 \mathrm{a} 8 \mathrm{~Hz}$, que coincidem com os valores indicados pela MEF (Figura 7) e com os valores obtidos da prova de carga realizada em 2011, indicados na Figura 8.

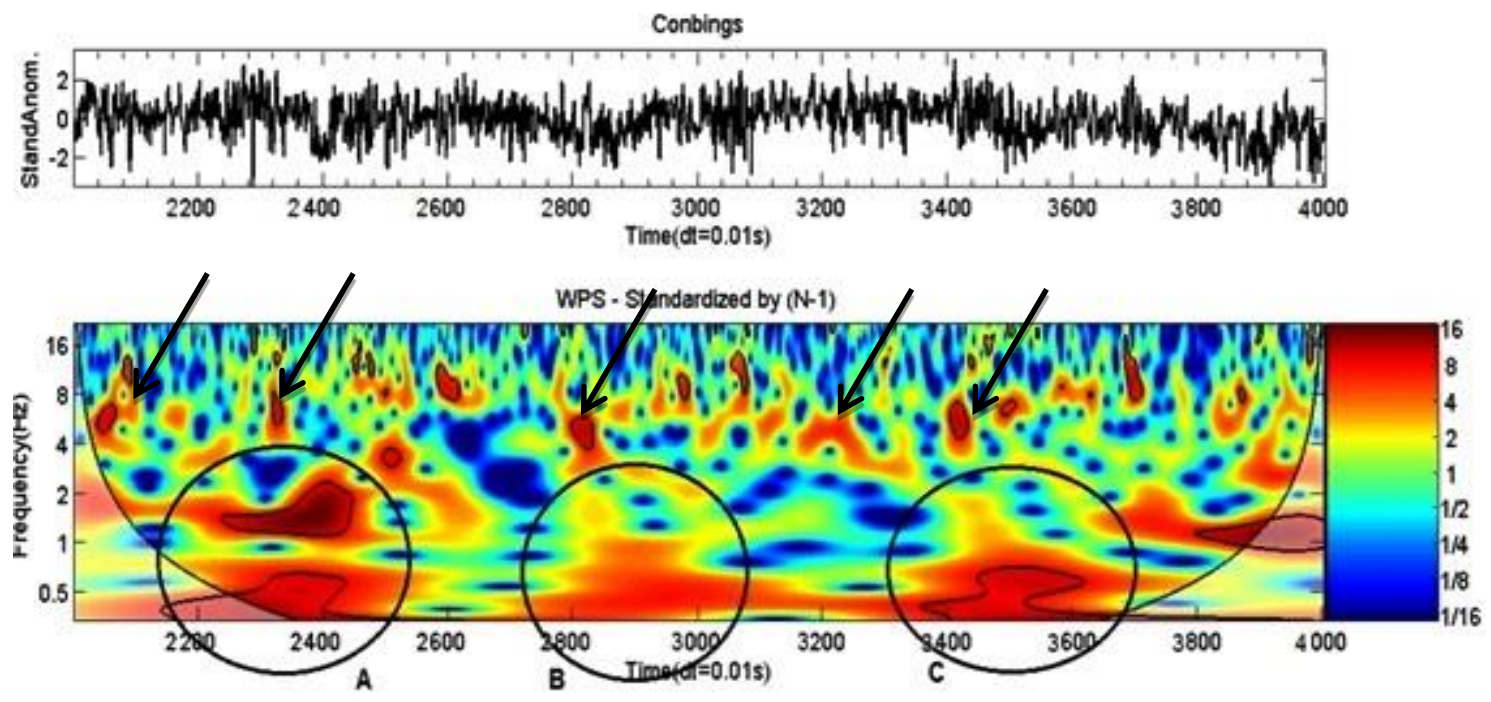

Figura 16: CWT dos resíduos da série temporal em observações entre 2000-4000, com nível de significância em $5 \%$ limitado pelo COI.

\section{ANÁLISES E CONCLUSÕES}

Os resultados obtidos indicaram a possibilidade de aplicação do método que envolve a combinação de Sistema de Posicionamento Global, Método dos Resíduos da Fase e CWT como uma ferramenta de monitoramento de deflexões milimétricas de tabuleiro de pontes de pequeno e médio porte. Os dados permitiram detectar as deflexões verticais com amplitude pico a pico de 3,5 $\mathrm{mm}$, com nível de confiança de $95 \%$. Estes valores foram confrontados com valores resultantes de métodos clássicos de monitoramento do comportamento dinâmico de estruturas como a Modelagem por Elementos Finitos e prova de carga dinâmica.

Os dados resultantes dos testes de calibração, com aplicação de deslocamento vertical com frequência e amplitude conhecidas pelo oscilador na antena GPS móvel apresentaram, na CWT, alta concentração de energia em torno de $0,4 \mathrm{~Hz}$, coincidindo como valor da frequência de oscilação configurada no oscilador.

Os testes realizados na ponte com os receptores GPS resultaram em valores de frequência e amplitude da deflexão vertical coincidentes com os valores provenientes da Modelagem por Elementos Finitos e prova de carga dinâmica. Frente ao exposto, conclui-se que a combinação proposta entre o uso de receptores GPS com alta taxa de dados $(100 \mathrm{~Hz})$ com técnicas de filtragem 
CWT permite detectar, com nível de confiança de $95 \%$ as ondas senoidais oriundas de deflexões verticais de tabuleiro de ponte de concreto com vão de $30 \mathrm{~m}$.

As próximas etapas da pesquisa prevêem a análise do tráfego local e geração de uma biblioteca de resposta espectral de excitação do vão de $30 \mathrm{~m}$ aos diversos tipos de veículos trafegam pela ponte, através da análise por Wavelets e descrição do movimento do tabuleiro durante a travessia dos veículos. Também está previsto a realização de medidas concomitante com o registro do tráfego através de filmagem.

O GPS através do Método dos Resíduos de Fase apresenta, até o momento, forte indicação que pode ser utilizado como metodologia de instrumentação complementar não só em grandes pontes estaiadas e suspensas, mas também em pontes menores e de estrutura rígida, como as de concreto.

\section{AGRADECIMENTOS}

Os autores agradecem ao grupo de pesquisa do Prof. Dr.Túlio N. Bittencourt do Departamento de Engenharia de Estruturas e Fundações da Escola Politécnica da USP pela oportunidade de participação em medições na ponte sobre o Rio Jaguari; ao Laboratório de Topografia e Geodésia do Departamento de Engenharia de Transportes da Escola Politécnica da USP pelo empréstimo das antenas JAVAD chokering; ao IFSULDEMINAS pelo apoio com infraestrutura para construção de marco geodésico próximo da ponte; ao CNPq pela bolsa de produtividade PQ2 $\mathrm{n}^{\mathrm{o}}$. 304371/2013-0.

\section{REFERÊNCIAS}

Andrade, Rodolfo. G. M. Monitoramento de curta duração de uma ponte curva em concreto armado: um estudo de caso. 2012. 144 f. Dissertação (Mestrado) - Escola Politécnica da Universidade de São Paulo, São Paulo, 2012.

Andrade, Rodolfo. G. M.; Trautwein, Leandro. M and Bittencourt, Túlio N. Comparison and calibration of numerical models from monitoring data of a reinforced concrete highway bridge. IBRACON, São Paulo, v. 6, n.1, p. 121-138, 2013.

ANTTRDT PROJETO 4 SGP/AFD. Relatório Técnico do Projeto 4 SGP/AFD. ANTT. 2012.

Araujo Neto, João O.; Trabanco, J. L. A.; Larocca, A. P. C.; Barbosa, A. C. B. and Schaal, R. E. Monitoring the Vertical Deflections of the Small Concrete Bridge with the adapted Phase Residual Method using High Rate GPS Data. In: $2^{\text {nd }}$ Joint International Symposium on Deformation Monitoring (JISDM), Nottingham, Inglaterra. 2013.

Azarbad, Milad. R. and Mosavi, Mahmood. R. A. New Method to Mitigate Multipath Error in Single-Frequency GPS Receiver with Wavelet Transform. GPS Solutions, v. 18, n. 1, p. 189-198. 2013.

Barbosa, Augusto C. B. Oscilações Intrasazonais no Indo-Pacífico e na Zona de Convergência do Atlântico Sul: Estudo observacional e numérico. Tese (Doutorado), Departamento de Ciências Atmosféricas do Instituto de Astronomia, Geofísica e Ciências Atmosféricas, Universidade de São Paulo, 243 p. 2012. 
Barbosa, Augusto C. B.; Blitzkow, D. Wavelet: History and Application. Lecture Notes. Institute of Astronomy, Geophysics and Atmospheric Sciences - University Sao Paulo - IAG/USP and POLI/USP.2008.

Beshr, Ashraf and Kaloop, Mosbeh. Monitoring Bridge Deformation Using Auto-Correlation Adjustment Technique for Total Station Observations. Positioning, v. 4 n. 1, p. 1-7, 2013.

Çelebim, Muhterem. GPS in dynamic monitoring of long-period structures. Soil Dynamics and Earthquake Engineering, v.20, Issues 5-8, p. 477-483, 2000.

Daubechies, Ingrid.; Mallat, Stéphane and Willsky, Alan. S. Introduction to the special issue on Wavelet Transforms and Multiresolution Signal Analysis. IEEE Transactions on Information Theory, v. 38, n.2, p. 528-531, 1992.

Goswami, Jaideva. C. and Chan, Andrew. K. Fundamentals of wavelets. Microwave and Optical Engineering. Wiley Interscience, New Jersey, 2nd edition, 2011.

Guo, Jinjun, Xu, L., Dai, Lianjun., Mcdonald, Mike, Wu, Jianping, and Li, Yanying. Application of the Real-Time Kinematic Global Positioning System in Bridge Safety Monitoring. Journal of Bridge Engineering, v.10(2), p.163-168, 2005.

Im, Seok B.; Hurlebaus, Stefan and Kang, Young. Summary Review of GPS Technology for Structural Health Monitoring. J. Struct. Eng. v. 139, SPECIAL ISSUE: Real-World Applications for Structural Identification and Health Monitoring Methodologies, p.1653-1664, 2013.

Kaloop, Mosbeh, Elbeltagi, Emad, and Elnabwy, Mohamed Bridge Monitoring with Wavelet Principal Component and Spectrum Analysis Based on GPS Measurements: Case Study of the Mansoura Bridge in Egypt. J. Perform. Constr. Facil. (ASCE), SPECIAL ISSUE, 2013.

Kumar, Jeethendra P. K, and Jolly, Naresh Michelson Interferometer, Kamaljeeth Instrumentation \& Service Unit.India, v. 4, n.3, p. 180-192, 2004.

Larocca, Ana P. C. ; Schaal, Ricardo e.; Guimarães, Gabriel; Blitzkow, Denizar. Detection of Low Frequency Structures Oscillations on L1 GPS signal by Wavelets Analysis - Application on Monitoring Bridges. IUGG 2011 General Assembly, in Melbourne, Australia, 28 June - 7 July 2011, 2011.

Larocca, Ana P. C. and Schaal, Ricardo. Filtering techniques applied on raw carrier phase for GPS detecting small dynamic displacements. Boletim de Ciências Geodésica, Curitiba, Brasil, v. 16, n. 1, p.177-188, 2010.

Larocca, Ana P. C. e Schaal, Ricardo E. (2005). Millimeters in motion - dynamic response precisely measured. GPS World, Cleveland, v. 16, n. 1, p. 16-24, 2005.

Larocca, Ana P. C. O uso do GPS como instrumento de controle de deslocamentos dinâmicos de obras civis - aplicação na área de transportes. Tese de Doutorado. Departamento de Engenharia de Transportes. Escola de Engenharia de São Carlos, 2004.

Larocca, Ana P. C. O uso do GPS como instrumento de controle de deslocamentos dinâmicos de obras civis - aplicação na área de transportes. 2004. 203 f. Tese (Doutorado) - Escola de Engenharia de São Carlos, Universidade de São Paulo, São Carlos, 2004.

Larocca, Ana P. C.; Schaal, Ricardo e. and Barbosa Augusto C. B. Improving Detection of Low Frequency Vibrations using High Rate Data and Filtering Techniques in Time Series of GPS Baseline. In:22nd International Meeting of the Satellite Division of The Institute of Navigation, Savannah, GA, p. 1867-1875. September, 2009. 
Larocca, Ana P. C.; Schaal, Ricardo E.; Santos, Marcelo C. L1 GPS as Tool for Monitoring the Dynamic Behavior of Large Bridges. Global Navigation Satellite Systems - From Stellar to Satellite Navigation. 1. ed. New York :In Tech. v. 1, p. 117-144, 2013.

Morettin, Pedro A. Ondas e Ondaletas: Da Análise de Fourier à Análise de Ondaletas de Séries Temporais. 2ed. São Paulo: Editora USP. 320 p., 2014.

Morlet, Jean. Sampling Theory and Wave Propagation. NATO ASI Series, v. 1, p. 233-261 Springer, Berlin, 1983.

Moschas, Fannis; Avallone, Antonio; Moschonas, Nikolaos; Saltogianni, Vasso and Stiros, Stathis. Assessment of accuracy of PPP for very-hight-frequency dynamic, satellite positioning and earthquarke modeling. EGU General Assembly, 1" ${ }^{\text {nd }}$, 2012, Vienna, Austria, v. 1, p. 42-52, 2012.

Nguyen, Romain. Y.; Del-Castillo-Negrete, Diego; Schneider, Kai; Farge, Marie and Chen, Guangye. (2010) Wavelet-based density estimation for noise reduction in plasma simulations using particles. Journal of Computational Physics, v. 229, n. 8, p. 2821-2839, 2010.

Roberts, Gethin W.; Meng, Xiaolin and Dodson, Alan H. Integrating a Global Positioning System and Accelerometers to Monitor the Deflection of Bridges. Journal of Surveying Engineering (ASCE), v. 130, n. 2, p. 65-72, 2004.

Schaal, Ricardo E. and Larocca, Ana P. C. A Methodology for Monitoring Vertical Dynamic SubCentimeter Displacements with GPS. GPS Solutions, New York, v. 5, n.3, p. 15-18, 2002.

Schaal, Ricardo E.; Larocca, Ana P. C. and Guimarães, Gabriel N. Use of a single L1 GPS receiver for monitoring structures: first results of detection of millimetric dynamic oscillations. Journal of Surveying Engineering. v. 138(2), n. 2, p. 92-95, 2012.

SINAENCO (2011). Sindicato da Arquitetura e da Engenharia. Infra-Estrutura da Cidade de São Paulo: Prazo de Validade Vencido, São Paulo (http://www.sinaenco.com.br/default.asp), 2011.

Souza, Eniuce M., Monico, João F. G. e Pagamisse, Aylton. Redução do efeito do multicaminho de frequiências alta e baixa no posicionamento relativo cinemático utilizando wavelets: resultados preliminares. Boletim de Ciências Geodésicas (Impresso), v. 15, p. 142-156, 2009.

Torrence, Christopher and Compo, Gilbert P. A. Practical Guide to Wavelet Analysis. Bulletin of the American Meteorological Society, v. 79, p. 61-78, 1998.

Yi, Ting-Hua; Li, Hong-Nan and Gu, Ming. Experimental assessment of high-rate GPS receivers for deformation monitoring of bridge. Measurement, v. 46, n. 1, p. 420-432, 2013.

(Recebido em junho de 2014. Aceito em dezembro de 2014). 